\title{
Tribological Properties of Plasma Sprayed Alumina, Alumina-Titania and Alumina-Zirconia Coatings
}

\author{
L. Marcinauskas ${ }^{a, b}$, M. MilieŠKA ${ }^{b, *}$, J.S. MatheW ${ }^{a}$, \\ V. DOVYdAitis ${ }^{a}$, R. KĖŽElis ${ }^{b}$ AND S. TUČKUTE் ${ }^{c}$ \\ ${ }^{a}$ Department of Physics, Kaunas University of Technology, \\ Studentu Str. 50, LT- 51368 Kaunas, Lithuania \\ ${ }^{b}$ Plasma Processing Laboratory, Lithuanian Energy Institute, \\ Breslaujos Str. 3, LT-44403 Kaunas, Lithuania \\ ${ }^{c}$ Center for Hydrogen Energy Technologies, Lithuanian Energy Institute, \\ Breslaujos Str. 3, LT-44403 Kaunas, Lithuania \\ Doi: 10.12693/APhysPolA.138.656 \\ *e-mail: mindaugas.milieska@lei.lt
}

\begin{abstract}
Alumina, alumina-titania and alumina-zirconia coatings were formed on stainless steel (AISI 304L) via atmospheric plasma spraying. The surface morphology, elemental composition and phase structure of the as-sprayed coatings were investigated by scanning electron microscopy, energy dispersive X-ray spectroscopy and X-ray diffraction. The influence of feedstock powder nature on the tribological properties of the coatings were measured under dry-sliding conditions. The energy dispersive X-ray spectroscopy measurements indicated that the amount of zirconium and titanium on the surface of the coatings was 0.76 wt. $\%$ and 3.9 wt.\%, respectively. The friction coefficient and wear rate of the steel substrate was 0.75 and $1.29 \times 10^{-4} \mathrm{~mm}^{3} /(\mathrm{N} \mathrm{m})$, respectively. It was demonstrated that the addition of titania or zirconia enhanced the friction coefficient of the composite alumina coatings up to 0.63 and 0.65 , which was $\approx 12 \%$ and $\approx 16 \%$ higher when compared to alumina coating. In addition to the increase of the friction coefficient values, all as-sprayed coatings demonstrated superior wear resistance when compared to the steel substrate.
\end{abstract}

topics: plasma spraying, alumina-zirconia, alumina-titania coatings, tribological properties

\section{Introduction}

Alumina coatings have found a pre-eminent place in the engineering industry owing to their varied merits such as high hardness, resistance to wear, insulation characteristics, durability, etc. The alumina coatings are widely used for the protection of the metallic surfaces in order to increase the lifetime of various parts [1-3]. One of the more efficient ways to produce these coatings on metallic surfaces is by plasma spraying. The advantages resulting from applying this process are high flame temperature, increased particle velocity, commendable surface properties, etc. [4-6]. The tribological properties of the coatings are quite dependent on the plasma spraying parameters as well on other parameters, e.g. the additive material used.

Within plasma-spraying parameters the torch power, spraying distance and plasma-gas composition are some of the imperatives [4-7]. Scientists quite often used an argon-nitrogen or argonhydrogen plasma. It is uncommon, however, to find an air-hydrogen plasma [8-10], although the reduction of the process cost, versatility and efficacy seem to be relatively better, as we observed in our previous work [7].
$\mathrm{Al}_{2} \mathrm{O}_{3}$ coatings in general have a high wear resistance but their toughness is not as high as the former property's. To make up for this, an inclusion of a material such as zirconia may ensure both high strength and toughness [11]. The friction coefficients and wear rates of as-deposited and mechanically post-treated (dry blasting process and mechanical abrasive polishing) alumina coatings were found to be in the range from 0.6 to 0.8 and the wear rates were $\sim(1-3) \times 10^{-5} \mathrm{~mm}^{3} /(\mathrm{N} \mathrm{m})[12]$. In another case, the friction coefficient of alumina varied from 0.61 to 0.75 with different material grades [9]. With a reinforcement of $25 \mathrm{wt} . \%$ of zirconia into alumina, it was found that the friction coefficient was 0.45 , indicating a tribological condition of superior hardness and toughness as compared with the properties of the individual materials [11]. Another additive such as titania makes a higher improvement of the coating properties possible as it aids in the proliferation of the fracture toughness: the resistance to fracture in the presence of inevitable defects/cracks, as well as the reduction of the porosity due to lower melting temperature of $\mathrm{TiO}_{2}[13,14]$. It was demonstrated that with 3 wt. $\%$ of $\mathrm{TiO}_{2}$ to $\mathrm{Al}_{2} \mathrm{O}_{3}$, the friction coefficient subject to plasma spraying conditions was found to 
be between 0.68 and 0.80 and with 13 wt.\% of titania it was between about 0.66 and 0.77 , respectively $[15,16]$. The addition of zirconia and titania into alumina coating improves the toughness, corrosion resistance and could result in better tribological properties [11, 15-17]. It should be noted that the applied plasma spraying technique for the formation of the coatings on thick and large-size metallic parts is quite common [1]. However, it is a challenge to spray high quality coatings on the thin metallic parts due to overheating of the samples.

Our work, therefore, aims to study the structure and tribological properties of air-hydrogen formed plasma sprayed coatings on thin substrates of pure alumina, alumina-zirconia $\left(\mathrm{Al}_{2} \mathrm{O}_{3}-5\right.$ wt.\% $\left.\mathrm{ZrO}_{2}\right)$ and alumina-titania $\left(\mathrm{Al}_{2} \mathrm{O}_{3}-3\right.$ wt. $\left.\% \mathrm{TiO}_{2}\right)$.

\section{Experimental}

The substrates for coating samples were prepared from AISI 304L steel and the dimensions were $40 \times 10 \times 1.5 \mathrm{~mm}^{3}$. The plasma torch used in this work for the preparation of coatings was designed and produced at the Lithuanian Energy Institute. Total air flow rate of $3.7 \mathrm{~g} / \mathrm{s}$ was used for plasma jet formation and the additional air flow rate of $0.75 \mathrm{~g} / \mathrm{s}$ was used for powder transportation into the plasma torch. In order to increase the plasma temperature inside the reactor nozzle and to intensify the heat transfer between the plasma jet and powder particles, the $\approx 0.1 \mathrm{~g} / \mathrm{s}$ flow rate of hydrogen was injected. $\mathrm{Al}_{2} \mathrm{O}_{3}$ (ALO-101), $\mathrm{Al}_{2} \mathrm{O}_{3}-3$ wt.\% $\mathrm{TiO}_{2}$ (ALO-105) and $\mathrm{ZrO}_{2}$ (ZRO-113/114) powders were used to produce the coatings. The powders were procured from PRAXAIR Surface Technologies, USA. The mixture of alumina and zirconia powders of $\mathrm{Al}_{2} \mathrm{O}_{3}-5$ wt. $\% \mathrm{ZrO}_{2}$ was prepared. The feedstock powders were dried before the deposition. The aluminium was sprayed as bonding coating in order to increase the adhesion between ceramic coatings and the substrate. The samples were placed in the distance of $70 \mathrm{~mm}$ from the plasma torch nozzle and the spraying lasted for $40 \mathrm{~s}$. The plasma torch arc current during the experiments was constant and equal to $200 \mathrm{~A}$, which provided the plasma torch power of $40 \mathrm{~kW}$. Such experimental conditions resulted in the mean plasma temperature at the injection place of the powders equal to $3820 \pm 50 \mathrm{~K}$, while the mean temperature of plasma at the exit nozzle of plasma torch was $3600 \pm 50 \mathrm{~K}$. More detailed information on the experimental setup and the methodology for plasma parameter calculations is found in [7].

The Hitachi S-3400N scanning electron microscope (SEM) and a portable surface roughness tester Mitutoyo Surftest SJ-210 Series (Version 2.00 with standard ISO 1997) was used for the surface morphology and roughness analysis of the coatings, respectively. The energy dispersive X-ray spectroscopy (EDX) method (Bruker Quad 5040 spectrometer, AXS Microanalysis $\mathrm{GmbH}$ ) was used for determining the elemental composition of the sprayed coatings. The structure of the coatings was analysed using X-ray diffraction (XRD) (Bruker D8 Discover) with a standard Bragg-Brentano focusing geometry in a $5^{\circ}-80^{\circ}$ range using the $\mathrm{CuK}_{\alpha}$ $(\lambda=0.154059 \mathrm{~nm})$ radiation. A ball-on-flat configuration on a tribometer (UMT-2, Bruker, USA) was used for measuring the tribological properties of prepared coatings and initial steel substrate. The sliding velocity of $0.05 \mathrm{~m} / \mathrm{s}$ for $3000 \mathrm{~s}$ (distance of $150 \mathrm{~m}$ ) with a constant normal load of $1.0 \mathrm{~N}$ was used for the tests. All tribological tests were performed in dry-sliding conditions at $21^{\circ} \mathrm{C}$ and relative humidity $\mathrm{RH}=20 \pm 5 \%$. As a counterpart, the $10 \mathrm{~mm}$ diameter $\mathrm{Al}_{2} \mathrm{O}_{3}$ ball (purity $99.5 \%$ and grade 10) was employed. The 3D white-light optical interferometer (Counter GT-K0, Bruker, USA), with the use of software Vision64 was applied for the examination of the amount of material removed from the coatings during the tribological tests.

\section{Results and discussion}

The surface images of the deposited coatings are given in Fig. 1. The surface microstructure of the $\mathrm{Al}_{2} \mathrm{O}_{3}$ coating demonstrates the presence of lamellar splats with a very low number of the partly melted particles (Fig. 1a, b). It should be noted that the microsize pores and microcracks were observed on the surface of the sprayed coating. The surface morphology of alumina-titania coating was quite similar to that of the $\mathrm{Al}_{2} \mathrm{O}_{3}$ coating (Fig. 1c, d). The insignificant increase in the amount of fully molten splats and a slight reduction of pores was observed. The surface of the alumina-zirconia coating was rather nonuniform in nature and larger size particles and more micropores were observed (Fig. 1e, f). The insignificant changes in the surface morphology of the coatings are related to the nature of the additive powders. The melting temperature of titania is lower than that of the $\mathrm{ZrO}_{2}$ powder, thus a more homogeneous coating with smaller size particles and less amount of pores was formed. It was demonstrated that the reduction of the porosity in $\mathrm{Al}_{2} \mathrm{O}_{3}$ coatings increases the microhardness and density of assprayed coatings [5]. Meanwhile, the production of interlaminar cracks would reduce the mechanical properties of the coatings [5, 17].

The surface roughness of the plasma sprayed alumina, alumina-zirconia and alumina-titania coatings was measured. It was estimated that the surface roughness $R_{a}$ and root-mean-square roughness $R_{q}$ values were very similar for pure alumina, i.e., $2.82 \mu \mathrm{m}$ and $2.85 \mu \mathrm{m}$, and for alumina-titania, i.e., $3.54 \mu \mathrm{m}$ and $3.57 \mu \mathrm{m}$. In the case of the aluminazirconia coating, its roughness was the highest, namely $R_{a}=3.5 \mu \mathrm{m}$ and $R_{q}=4.4 \mu \mathrm{m}$. Better melting (due to lower melting temperature) and bonding capabilities exhibited by titania in comparison to zirconia could be the reason for the reduced surface roughness. Further, the melting temperature 


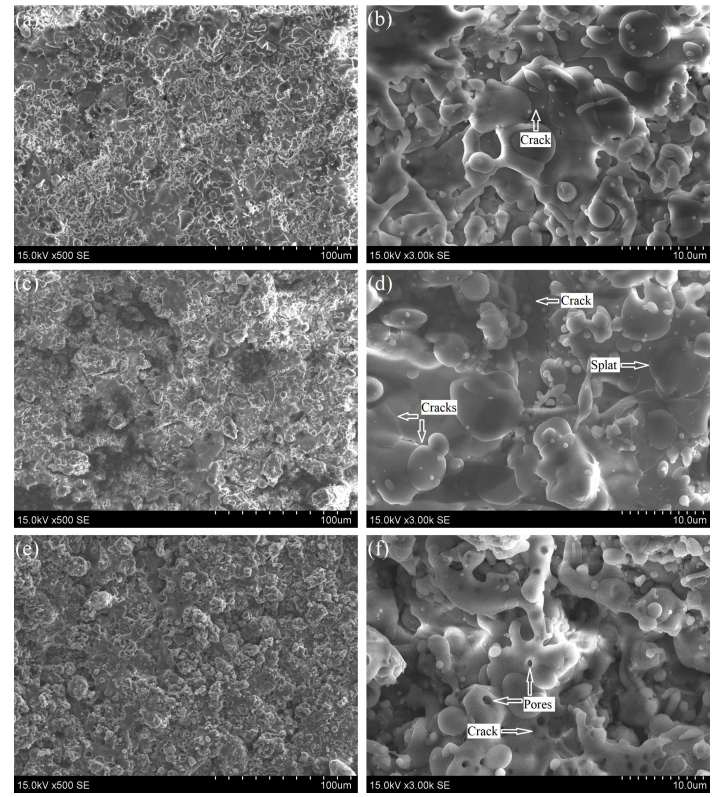

Fig. 1. SEM images of deposited coatings of $\mathrm{Al}_{2} \mathrm{O}_{3}$ (a, b), $\mathrm{Al}_{2} \mathrm{O}_{3}-3$ wt. $\% \mathrm{TiO}_{2}$ (c, d) and $\mathrm{Al}_{2} \mathrm{O}_{3}-5$ wt. $\%$ $\mathrm{ZrO}_{2}(\mathrm{e}, \mathrm{f})$.

of $\mathrm{Al}_{2} \mathrm{O}_{3}$ is about $2050{ }^{\circ} \mathrm{C}$ and the melting temperature of $\mathrm{ZrO}_{2}$ is about $2680^{\circ} \mathrm{C}$ [17]. Consequently, the addition of $\mathrm{ZrO}_{2}$ into the alumina powder resulted in higher surface roughness. The roughness of the polished steel substrate was $R_{a} \approx 0.25 \mu \mathrm{m}$ and $R_{q} \approx 0.32 \mu \mathrm{m}$.

The EDS measurements were used to investigate the surface composition of the deposited coatings. The $\mathrm{Al}_{2} \mathrm{O}_{3}$ coating consisted of aluminum $(\approx 50.3 \mathrm{wt} . \%)$ and oxygen $(\approx 48.5 \mathrm{wt} . \%)$ with a low amount $(\approx 1$ at. $\%)$ of impurities related to the composition of the powder and carbon. The aluminatitania coating consisted of $\mathrm{Al}(\approx 46.4 \mathrm{wt} . \%)$, $\mathrm{O}(\approx 48.7 \mathrm{wt} . \%)$ and $\mathrm{Ti}(\approx 3.9 \mathrm{wt} . \%)$. The oxygen content was $\approx 47.1$ wt. $\%$, aluminum -51.0 wt. $\%$, while zirconium's amount was $\approx 0.76$ wt. $\%$, when the alumina-zirconia powders mixture was used. It should be noted that all coatings have a low amount of impurities mainly related to the composition of feedstock powders. Goral et al. [18] demonstrated that even in nanostructured $\mathrm{Al}_{2} \mathrm{O}_{3}-13 \mathrm{TiO}_{2}$ coatings, the elemental composition varied considerably: for $\mathrm{Al}$ from 43.9 at.\% to 49.1 at. $\%$, for $\mathrm{O}$ from 46.1 at. $\%$ to 50.0 at. $\%$ and for Ti from 2.7 at.\% to 4.0 at. $\%$ [18].

The XRD patterns of pure $\mathrm{Al}_{2} \mathrm{O}_{3}$ and $\mathrm{Al}_{2} \mathrm{O}_{3}$ composite coatings are presented in Fig. 2. Both rhombohedral $\alpha-\mathrm{Al}_{2} \mathrm{O}_{3}$ and cubic $\gamma-\mathrm{Al}_{2} \mathrm{O}_{3}$ phases were present in all coatings [5, 14]. The peaks corresponding to various orientation $\alpha-\mathrm{Al}_{2} \mathrm{O}_{3}$ were found at $25.7^{\circ}(012), 35.4^{\circ}(104), 38.0^{\circ}(110), 43.5^{\circ}(113)$, $52.6^{\circ}(024), 57.7^{\circ}(116)$ and $68.4^{\circ}(300)$. The signal relating $\gamma-\mathrm{Al}_{2} \mathrm{O}_{3}$ phase was obtained at $19.6^{\circ}(111)$, $37.8^{\circ}(311), \quad 39.6^{\circ}(222), 46.0^{\circ}(400), 61.1^{\circ}(511)$ and $67.0^{\circ}(440)$ [5, 19]. The peaks located at $\approx 38.6^{\circ}, 44.9^{\circ}, 65.3^{\circ}$ and $78.4^{\circ}$ were attributed

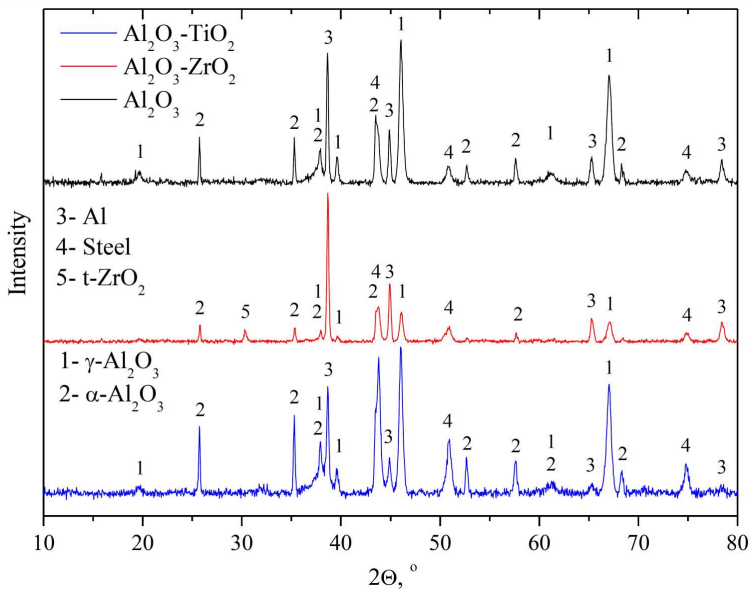

Fig. 2. The XRD patterns of $\mathrm{Al}_{2} \mathrm{O}_{3}$, $\mathrm{Al}_{2} \mathrm{O}_{3}-5$ wt. $\% \quad \mathrm{ZrO}_{2}$ and $\mathrm{Al}_{2} \mathrm{O}_{3}-3$ wt.\% $\mathrm{TiO}_{2}$ coatings.

to the adhesive aluminum layer. The peaks found at $\approx 43.8^{\circ}, 50.9^{\circ}$ and $74.8^{\circ}$ are due to the steel substrate. Since the amounts of $\mathrm{ZrO}_{2}$ and $\mathrm{TiO}_{2}$ in the feedstock powder were relatively small, the phase composition of composite coatings did not differ much when compared to the pure $\mathrm{Al}_{2} \mathrm{O}_{3}$ coating. In the $\mathrm{Al}_{2} \mathrm{O}_{3}-\mathrm{TiO}_{2}$ coating, it was impossible to distinguish peaks corresponding to $\mathrm{TiO}_{2}$ since their intensities were much lower when compared to the signal of $\mathrm{Al}_{2} \mathrm{O}_{3}$ peaks. In the case of $\mathrm{Al}_{2} \mathrm{O}_{3}-$ $\mathrm{ZrO}_{2}$ coatings, only one additional low intensity peak of tetragonal $\mathrm{t}-\mathrm{ZrO}_{2}$ (101) was obtained and it was located at $30.2^{\circ}[11,17]$. Although the addition of $\mathrm{Ti}$ or $\mathrm{Zr}$ oxides did not change the positions of main peaks or introduce significant amounts of new phases, it did influence the relative concentrations of $\alpha-\mathrm{Al}_{2} \mathrm{O}_{3}$ and $\gamma-\mathrm{Al}_{2} \mathrm{O}_{3}$. The most common method to evaluate relative $\alpha-\mathrm{Al}_{2} \mathrm{O}_{3}$ and $\gamma-\mathrm{Al}_{2} \mathrm{O}_{3}$ concentrations is described in [19]. Calculations were done using:

$$
\gamma-\mathrm{Al}_{2} \mathrm{O}_{3}(\%)=\frac{I_{\gamma-\mathrm{Al}_{2} \mathrm{O}_{3}(400)} \times 100 \%}{I_{\gamma-\mathrm{Al}_{2} \mathrm{O}_{3}(400)}+I_{\gamma-\mathrm{Al}_{2} \mathrm{O}_{3}(113)}},
$$

where $I_{\gamma-\mathrm{Al}_{2} \mathrm{O}_{3}(400)}$ and $I_{\gamma-\mathrm{Al}_{2} \mathrm{O}_{3}(113)}$ are the highest intensity peaks corresponding to $\gamma-\mathrm{Al}_{2} \mathrm{O}_{3}$ and $\alpha-\mathrm{Al}_{2} \mathrm{O}_{3}$ phases.

According to the calculations, the pure alumina coating consisted of $66.3 \%$ gamma phase and $34.7 \%$ alpha phase, alumina-titania coating $-62.1 \% \gamma-\mathrm{Al}_{2} \mathrm{O}_{3}$ and $37.9 \% \alpha-\mathrm{Al}_{2} \mathrm{O}_{3}$ phase and the composition of alumina-zirconia coatings were $49.5 \% \gamma-\mathrm{Al}_{2} \mathrm{O}_{3}$ and $50.5 \% \alpha-\mathrm{Al}_{2} \mathrm{O}_{3}$. The XRD results indicated that the gamma phase dominates over $\alpha-\mathrm{Al}_{2} \mathrm{O}_{3}$ phase in alumina and alumina-titania coatings. It indicates that most of the feedstock particles were fully melted in air-hydrogen plasma and due to rapid solidification of the aluminum oxide splats on the steel substrate, $\gamma-\mathrm{Al}_{2} \mathrm{O}_{3}$ phase was formed [5, 7, 14, 17]. Rong et al. [20] observed that the addition of yttria into the alumina coatings reduced the $\gamma-\mathrm{Al}_{2} \mathrm{O}_{3}$ phase content, 


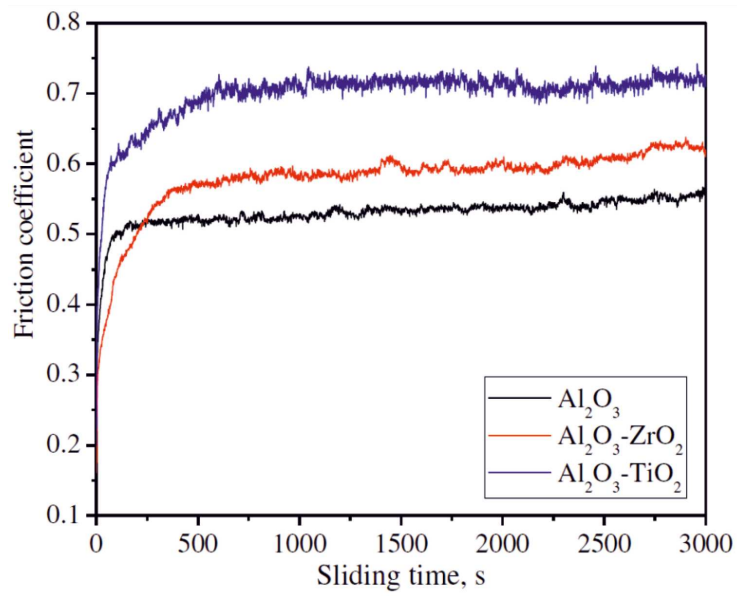

Fig. 3. Friction coefficient curves of as-sprayed coatings.

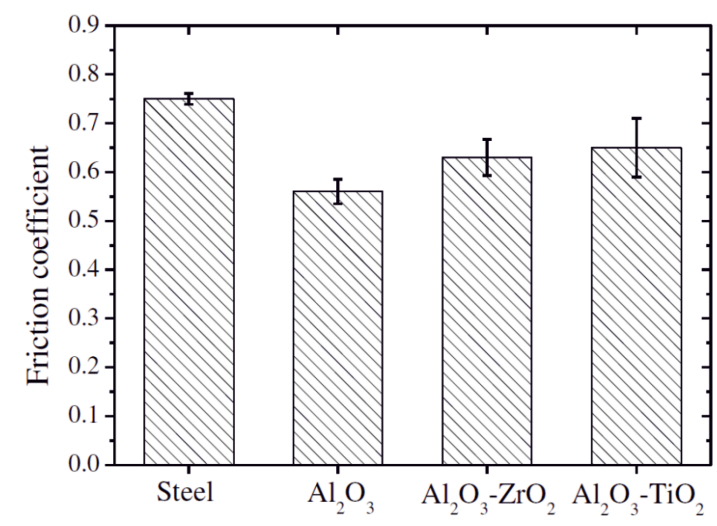

Fig. 4. Friction coefficient values of as-sprayed coatings and steel substrate.

due to the chemical reaction, reduced surface tension and interfacial energy. The addition of the zirconia powder could induce the same processes which lead to the stabilization of $\alpha-\mathrm{Al}_{2} \mathrm{O}_{3}$ phase and enhance its fraction in the $\mathrm{Al}_{2} \mathrm{O}_{3}-\mathrm{ZrO}_{2}$ coating. It was demonstrated that the microhardness of $\alpha-\mathrm{Al}_{2} \mathrm{O}_{3}$ is higher than that of $\gamma-\mathrm{Al}_{2} \mathrm{O}_{3}$ phase [17]. Di Girolamo et al. [14] have shown that the addition of $3 \mathrm{wt} . \% \mathrm{TiO}_{2}$ into alumina reduced the microhardness values, despite the enhancement of $\alpha-\mathrm{Al}_{2} \mathrm{O}_{3}$ phase fraction in the coating.

It could be perceived from Fig. 3 that the curves of the friction run of pure alumina were the least and with alumina-titania - the highest. The runningin state of pure alumina was the shortest, clocking at $\approx 250 \mathrm{~s}$, whereas with alumina-titania it was the highest, namely $\approx 750 \mathrm{~s}$. The friction coefficient curves for $\mathrm{Al}_{2} \mathrm{O}_{3}, \mathrm{Al}_{2} \mathrm{O}_{3}-\mathrm{ZrO}_{2}$ and $\mathrm{Al}_{2} \mathrm{O}_{3}-\mathrm{TiO}_{2}$ coatings ranged from $0.17-0.56,0.16-0.61$ and $0.2-0.71$, respectively (Fig. 4). It could clearly be seen that with additives such as zirconia and titania, which in general increase the toughness of the material, the average friction coefficient was also higher. With the spread of the additives being ploughedout with a reciprocating action of the counter body,
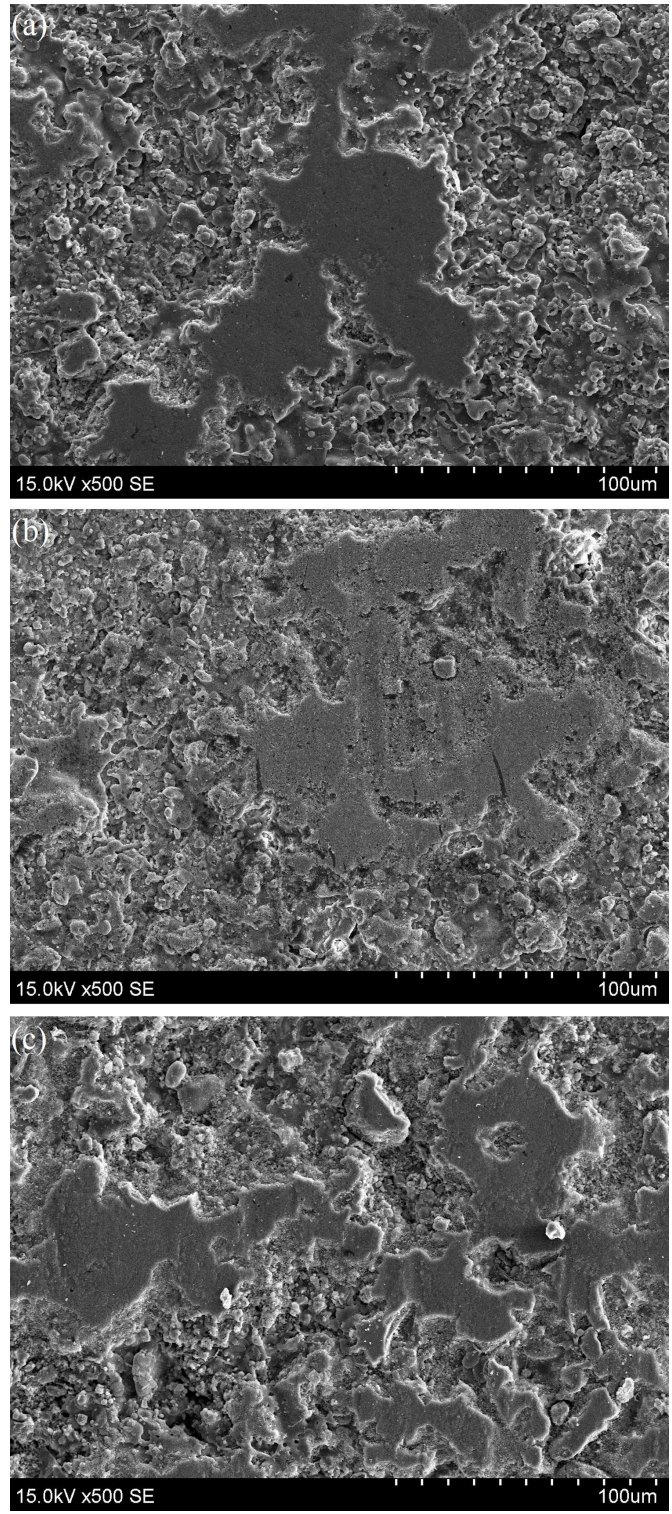

Fig. 5. SEM images of worn surfaces of $\mathrm{Al}_{2} \mathrm{O}_{3}$ (a), $\mathrm{Al}_{2} \mathrm{O}_{3}-3$ wt. $\% \mathrm{TiO}_{2}$ (b) and $\mathrm{Al}_{2} \mathrm{O}_{3}-5$ wt. $\% \mathrm{ZrO}_{2}$ (c) coatings.

the coating in any case was not completely destroyed (a sign of it having the COF close to unity). Thus, the friction runs of the coatings were well within the safety limits, not indicating substantial coating-delamination/destruction as also seen from the SEM images (Fig. 5).

The average friction coefficient measured to be the steady state average taken from 2000-3000 s indicated that pure alumina, alumina-zirconia and alumina-titania had an ascending nature to the tune of $0.56 \pm 0.025,0.63 \pm 0.037$ and $0.65 \pm 0.06$, respectively. The COF of the steel substrate was, however, recorded to be the highest at $0.75 \pm 0.011$. It was obtained that the friction coefficient of $\mathrm{Al}_{2} \mathrm{O}_{3}-15$ wt. $\% \mathrm{ZrO}_{2}$ composite coating at $3 \mathrm{~N}$ load was 0.75 . However, the variation of sliding time, sliding speed and applied load has huge influence on the friction coefficient values [21]. 
The elemental composition was measured at wear scars regions of the as-sprayed coatings. It should be noted that the gold layer was deposited on the as-sprayed coatings in order to obtain better images for 3D white-light optical interferometer. The EDS measurements were performed at $500 \times$ magnification at several places and average values were calculated. The alumina oxide coating was composed of aluminum (43.7 wt.\%) and oxygen (36.6 wt.\%), while the amount of gold was $\approx 18.3$ wt.\%. The surface composition of alumina-zirconia coating was $\mathrm{Al}$ (38.3 wt.\%), O (43.2 wt.\%), Zr (1.0 wt.\%) and Au (16.4 wt.\%). Aluminum (32.3 wt.\%), oxygen (32.5 wt.\%), titanium (2.7 wt.\%) and gold (31.6 wt.\%) were obtained in the wear scars of alumina-titania coatings. The wear scars of the sprayed coatings are shown in Fig. 5. The surface morphology after tribological tests of all coatings was very similar. The wear scars in the contact area were non-continuous and no additional cracks or delamination of the coatings were observed. It indicates good toughness and high adhesive strength between individual splats in the as-sprayed coatings [22]. The abraded areas on the surface of the coatings were obtained. However, the existence of the smoothened zone indicates that the $\mathrm{Al}_{2} \mathrm{O}_{3}$ ball interacted only with a limited surface area of the coatings. As a result, only very slight peeling of the highest hills was caused. The 3D interferometery was used to measure the profiles of wear scars. However, the surface roughness values between the non-affected and wear scars areas were in the same range. Thus, the amount of the removed material was very low and it was impossible to properly determine the wear rate of the coatings. The normalized wear rate (NWR) of the all as-sprayed coatings were found to be immeasurable owing to plastic deformations with no defined wear depth. However, for the steel substrate the NWR was determined to be $1.29 \times 10^{-4} \mathrm{~mm}^{3} /(\mathrm{N} \mathrm{m})$. This clearly indicates that the wear resistance of the as-sprayed coatings was definitively superior.

\section{Conclusions}

The $\mathrm{Al}_{2} \mathrm{O}_{3}, \mathrm{Al}_{2} \mathrm{O}_{3}-\mathrm{ZrO}_{2}$ and $\mathrm{Al}_{2} \mathrm{O}_{3}-\mathrm{TiO}_{2}$ coatings were deposited by plasma spraying. The elemental composition measurements indicated that the titanium and zirconium concentration in the $\mathrm{Al}_{2} \mathrm{O}_{3}-3$ wt. $\% \mathrm{TiO}_{2}$ and $\mathrm{Al}_{2} \mathrm{O}_{3}-5$ wt. $\% \mathrm{ZrO}_{2}$ coatings was 3.9 wt. $\%$ and 0.76 wt.\%, respectively. The incorporation of $\mathrm{ZrO}_{2}$ into the $\mathrm{Al}_{2} \mathrm{O}_{3}$ powders enhanced $(\approx 24 \%)$ the surface roughness of the coating. The $\gamma-\mathrm{Al}_{2} \mathrm{O}_{3}$ phase content in $\mathrm{Al}_{2} \mathrm{O}_{3}$ coating was almost twice as high as the phase fraction of $\alpha-\mathrm{Al}_{2} \mathrm{O}_{3}$. Meanwhile, the amount of $\gamma-\mathrm{Al}_{2} \mathrm{O}_{3}$ phase fraction in the $\mathrm{Al}_{2} \mathrm{O}_{3}$ $\mathrm{ZrO}_{2}$ was reduced and became equal to the $\alpha-\mathrm{Al}_{2} \mathrm{O}_{3}$ phase. The friction coefficient of the $\mathrm{Al}_{2} \mathrm{O}_{3}$ coating was the lowest $(\approx 0.56)$ and was $\approx 25 \%$ lower when compared to the $304 \mathrm{~L}$ steel. The friction coefficients of the as-sprayed $\mathrm{Al}_{2} \mathrm{O}_{3}-\mathrm{ZrO}_{2}$ and
$\mathrm{Al}_{2} \mathrm{O}_{3}-\mathrm{TiO}_{2}$ coatings were 0.63 and 0.65 , respectively. The surface views after the friction tests demonstrated that only a slight surface damage was obtained for as-sprayed coatings. The wear scars were non-continuous and only an insignificant peeling of the hilltops on the surfaces was observed. Meanwhile, the wear rate of AISI $304 \mathrm{~L}$ steel was $1.29 \times 10^{-4} \mathrm{~mm}^{3} /(\mathrm{N} \mathrm{m})$. The obtained results demonstrated that the as-sprayed coatings exhibited a superior wear resistance in dry sliding conditions and could significantly extend the service life of metallic parts under low load conditions.

\section{Acknowledgments}

This research has partly been supported by the Research, Development and Innovation Fund of Kaunas University of Technology (project grant No. PP-88G/19) and internal funding of the Lithuanian Energy Institute. The authors are grateful to Dr. M. Kalin from the University of Ljubljana for the possibility to perform tribological measurements.

\section{References}

[1] R.B. Heimann, Plasma Spray Coating Principles and Applications, Wiley-VCH, 2008.

[2] J. Kang, B. Xu, H. Wang, C. Wang, Tribol. Int. 73, 47 (2014).

[3] Y. Yang, Y. Wang, W. Tian, D. Yan, J. Zhang, L. Wang, Mater. Des. 65, 814 (2015).

[4] Z. Yin, S. Tao, X. Zhou, C. Ding, J. Eur. Ceram. Soc. 28, 1143 (2008).

[5] C. Wang, L. Fan, J. Fan, D. Zhang, H. Wang, J. Alloys Compd. 559, 152 (2013).

[6] M. Shahien, M. Suzuki, Surf. Coat. Technol. 318, 11 (2017).

[7] L. Marcinauskas, J.S. Mathew, M. Milieška, B. Thanigachalam, A. Kupec, R. Česnavičius, R. Kèželis, M. Kalin, Surf. Coat. Technol. 350, 401 (2018).

[8] E.P. Song, B. Hwang, S. Lee, N.J. Kim, J. Ahn, Mater. Sci. Eng. A 429, 189 (2006).

[9] S. Goel, S. Björklund, N. Curry, U. Wiklund, S.V. Joshi, Surf. Coat. Technol. 315, 80 (2017).

[10] C.J. Li, B. Sun, Thin Solid Films 450, 282 (2004).

[11] R. Younes, M.A. Braidai, A. Sadeddine, Y. Mouadji, A. Bilek, A. Benabbas, Trans. Nonferrous Met. Soc. China 26, 1345 (2016).

[12] A. Riedl, N. Schalk, C. Czettl, B. Sartory, C. Mitterer, Wear 289, 9 (2012). 
[13] A.K. Krella, A. Krupa, M. Gazda, A.T. Sobczyk, A. Jaworek, Ceram. Int. 43, 12126 (2017).

[14] G. Di Girolamo, A. Brentari, C. Blasi, E. Serra, Ceram. Int. 40, 12861 (2014).

[15] A.R.M. Sahab, N.H. Saad, S. Kasolang, J. Saedon, Proced. Eng. 41, 1689 (2012).

[16] S. Guessasma, M. Bounazef, C. Coddet, Mater. Charact. 52, 237 (2004).

[17] Y.D. Chen, Y. Yang, Z.H. Chu et al., Appl. Surf. Sci. 431, 93 (2018).

[18] A. Goral, W. Zorawski, L. LitynskaDobrzynka, Mater. Charact. 96, 234 (2014).
[19] K.A. Khor, F.Y.C. Boey, X.L. Zhao, L.H. Cao, Mater. Sci. Eng. A 300, 203 (2001).

[20] J. Rong, K. Yang, Y. Zhuang, H. Zhao, Ch. Liu, Sh. Tao, Ch. Ding, Surf. Coat. Technol. 316, 1 (2017).

[21] S.H. Kim, S.-P. Hannula, S.W. Lee, Surf. Coat. Technol. 210, 127 (2012).

[22] Y. An, Sh. Li, G. Hou, X. Zhao, H. Zhou, J. Chen, Ceram. Int. 43, 5319 (2017). 